\title{
Analysis on the impact of aerosol optical depth on surface solar radiation in the Shanghai megacity, China
}

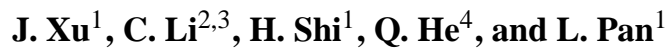 \\ ${ }^{1}$ Shanghai Center for Urban Environmental Meteorology, Shanghai Meteorological Bureau, Shanghai, China \\ ${ }^{2}$ Department of Atmospheric and Oceanic Sciences, School of Physics, Peking University, Beijing, China \\ ${ }^{3}$ Laboratory for Climate and Ocean-Atmosphere Studies, Peking University, Beijing, China \\ ${ }^{4}$ Shanghai Center for Satellite Remote-sensing and Application, Shanghai Meteorological Bureau, Shanghai, China
}

Received: 12 December 2010 - Published in Atmos. Chem. Phys. Discuss.: 7 January 2011

Revised: 19 March 2011 - Accepted: 25 March 2011 - Published: 6 April 2011

\begin{abstract}
This study investigated the decadal variation of the direct surface solar radiation (DiSR) and the diffuse surface solar radiation (DfSR) during 1961-2008 in the Shanghai megacity as well as their relationships to Aerosol Optical Depth (AOD) under clear-sky conditions. Three successive periods with unique features of long term variation of DiSR were identified for both clear-sky and all-sky conditions: a "dimming" period from the late 1960s to the mid 1980s, a "stabilization"/"slight brightening" period from the mid 1980s to the mid 1990s, and a "renewed dimming" period thereafter. During the two dimming periods of DiSR, DfSR brightened significantly under clear-sky conditions, indicating that change in atmospheric transparency resulting from aerosol emission has an important role on decadal variation of surface solar radiation (SSR) over this area. The analysis on the relationship between the Moderate-resolution Imaging Spectroradiometer (MODIS) retrieved AOD and the corresponding hourly measurements of DiSR and DfSR under clear-sky conditions clearly revealed that AOD is significantly correlated and anti-correlated with DfSR and DiSR, respectively, both above $99 \%$ confidence in all seasons, indicating the great impact of aerosols on SSR through absorption and/or scattering in the atmosphere. In addition, both AOD and the corresponding DiSR and DfSR measured during the satellite passage over Shanghai show obvious weekly cycles. On weekends, AOD is lower than the weekly average, corresponding to higher DiSR and lower DfSR, while the opposite pattern was true for weekdays. Less AOD on weekends due to the reduction of transportation and industrial activities results in enhancement of atmospheric transparency under cloud free conditions so as to increase DiSR and de-
\end{abstract}

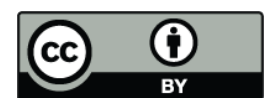

Correspondence to: $\mathrm{C} . \mathrm{Li}$ (ccli@pku.edu.cn) crease DfSR simultaneously. Results show that aerosol loading from the anthropogenic emissions is an important modulator for the long term variation of SSR in Shanghai.

\section{Introduction}

Solar radiation at the Earth's surface (surface solar radiation, SSR) is the ultimate energy source for life on the planet. It governs diverse surface processes, such as evaporation and associated hydrological cycles. Various studies analyzing long-term surface radiation measurements suggested a widespread decrease in SSR between the 1950s and 1980s ("global dimming") and a partial recovery or level off beyond the 1990s, which is in line with some independent long-term proxy observations of sunshine duration, diurnal temperature range, pan evaporation and more recently satellite-derived estimates (Wild et al., 2005; Wild, 2009). A number of studies which focus on the region of China discovered some similar results on SSR variations. For example, Liang and Xia (2005) found an overall decreasing trend in SSR in China between 1961 and 2000 by an average of $3.3 \%$ decade $^{-1}$ $\left(\sim 5 \mathrm{~W} \mathrm{~m}^{-2} \mathrm{decade}^{-1}\right)$ at 38 out of 42 sites, while Che et al. (2005) concluded a decrease of $4.5 \mathrm{~W} \mathrm{~m}^{-2}$ decade $^{-1}$ at 64 sites over the same time period. Similarly, for the period between 1955 and 2000, Qian et al. (2006) determined an average decrease of $3.1 \mathrm{~W} \mathrm{~m}^{-2}$ decade $^{-1}$ in SSR at 85 sites in China, and Shi et al. (2008) found a decreasing trend of $2.5 \%$ decade $^{-1}\left(\sim 3.8 \mathrm{~W} \mathrm{~m}^{-2}\right.$ decade $\left.^{-1}\right)$ with a more pronounced dimming of $4.6 \% \mathrm{decade}^{-1}$ for the sub-period of 1961 to 1989.

The decadal and inter-annual variations of SSR can be caused by many reasons, such as changes of cloud optical properties, radiative active gases, and mass and optical properties of aerosols. Of these causes, clouds and aerosols have

Published by Copernicus Publications on behalf of the European Geosciences Union. 
been regarded as the most important ones to explain the dimming and brightening phenomenon. These two candidates are not completely independent of each other because of their interactions in various ways. The question of which one is the more important contributor for changing the SSR is not confirmed by previous studies because the relative importance of aerosols, clouds and aerosol-cloud interactions may differ depending on the region and pollution level (Wild, 2009). Several studies suggested that the increasing anthropogenic aerosol amount due to air pollution is a major factor for the SSR decreasing between the 1960s and the 1990s in China and the subsequent partial recovery in SSR is also in line with some reduction in fossil fuel emissions (Che et al., 2005; Streets et al., 2006; Qian et al., 2007). As is broadly agreed in recent studies, the cause of dimming and/or brightening is quite inconsistent in regions depending on different influence factors of SSR. It was revealed by Norris and Wild (2009) that aerosol was the major modulator in the first half of the SSR trend during 1971-1989, while cloud cover reduction was the major modulator in the second half of the SSR trend during 1990-2002 in China. Xia (2010) suggested a complex spatial-temporal variation of decadal trends in SSR with a renewed dimming during 1991-2005 in North China, while a slight brightening appeared in South China. Now that the SSR variations tend to be more complicated in different regions especially since the new millennium, it suggests that the influences of aerosols and/or clouds as well as their interactions on SSR are strongly dependant on regional climate and pollution levels. Consequently, investigations on SSR and associated factors in some typical areas such as megacities or remote sites are necessary for the purpose to better understand the leading cause of SSR variations in a more detailed and accurate way.

In recent years, long-term SSR records were investigated under all-sky and clear-sky conditions to exclude possible effects of changes of cloud cover and cloud properties on SSR. Furthermore, the partition of SSR into direct surface solar radiation (DiSR) and diffuse surface solar radiation (DfSR) provides additional insight to analyze the origins of SSR dimming and brightening (Che et al., 2005; Qian et al., 2007). Clear-sky changes in China, which have been studied by Qian et al. (2006), showed a downward trend from the 1960 s to the 1990s and a partial recovery thereafter, which is in line with the changes noticed under all-sky conditions. As is well known, aerosols can change SSR by scattering and/or absorbing solar radiation in its transfer path from the top of atmosphere to the Earth surface. However, the columnintegrated aerosol observation such as Aerosol Optical Depth (AOD) has not been used directly to investigate its impact on SSR variation in China because of the lack of relative long term AOD observations and high temporal resolution of SSR records (at least hourly data). Streets et al. (2006) suggested that a two-decadal trend between 1980 and 2000 of $\mathrm{SO}_{2}$ and black carbon which together contribute about onethird of global aerosol optical depth has been thought as a likely explanation of the global dimming/brightening transition. The goal of this study is to elucidate the role of aerosol on the secular variation of SSR through analysis on AOD, DiSR and DfSR measured in Shanghai, the largest megacity of China, and to investigate a new insight into the origin of dimming and brightening in the east china monsoon region (Wu et al., 2009; Li et al., 2010). This paper is organized as follows. Data and methodology are presented in Sect. 2. In Sect. 3.1, analyses on decadal variations of DiSR and DfSR under clear-sky and all-sky conditions are conducted to determine the impact of aerosol on SSR. In Sect. 3.2, relationships between AOD and DiSR and DfSR are investigated. The weekly variations of AOD as well as the corresponding hourly DiSR and DfSR measured during the satellite passage are studied in Sect. 3.3. The discussion and conclusions are given in the last section.

\section{Data and methodology}

\subsection{Data}

There is only one pyranometer site $\left(31.17^{\circ} \mathrm{N}, 121.43^{\circ} \mathrm{E}\right)$ in the surrounding area of the Shanghai megacity. It is a classone site of Chinese Meteorological Administration (CMA) located in an industrial area and belongs to the SSR monitoring network of CMA. SSR, DiSR and DfSR have being measured at this site since the end of 1950s. The Yanishevsky thermoelectric pyranometer was used to measure SSR before 1991 and since then was replaced by the DFY-4 pyranometer. The uncertainty of the measurements has been estimated to be less than 5\% (Shi et al., 2008). Daily DiSR and DfSR data measured at this site from 1961 to 2008 are used in this study to examine their decadal variations except for the year 1991 because of the instrument replacement. Groundbased observations of Total Cloud Cover (TCC) from 1961 to 2008 at the same site are also used to determine the clear-sky condition which is defined as daily mean TCC (an average of 4 TCC observations each day at 02:00, 08:00, 14:00:00 and 20:00:00 LT) is less than 0.10 (Qian et al., 200)]. The aforementioned DiSR, DfSR and TCC data were provided by the Climate Data Center, Chinese Meteorological Bureau (CDC/CMA) and have partially been used in several studies in the past to investigate secular trends of SSR and cloud cover in China (e.g., Qian et al., 2006, 2007; Xia, 2010).

The ground-based AOD monitoring in Shanghai started from 2007 with data for less than 2 years. Thus the AOD product from the MODIS is selected in this study due to its relatively long term record and high accuracy. The MODIS instrument is one of the first passive satellite radiometers designed to retrieve aerosols over land and ocean. The instrument aboard the Terra (EOS AM) and Aqua (EOS PM) satellites provides high radiometric sensitivity (12 bit) in 36 spectral bands ranging in wavelength from $0.4 \mu \mathrm{m}$ to $14.4 \mu \mathrm{m}$ (http://modis.gsfc.nasa.gov/about/design.php). Kaufman et 
al. (1997) introduced an approach to retrieve aerosols over land from the MODIS measurements. The algorithm has been modified periodically and designated by different versions of collections since the launch of MODIS(Remer et al., 2005). Previous validation of the MODIS collection 005 showed much improved retrievals of AOD (Levy et al., 2007; Mi et al., 2007). This data has been widely used for aerosol and climate change related studies in China (e.g., Chu et al., 2002; Li et al., 2003; Yang et al., 2010). The daily level2 AOD data (Collection 005) at $550 \mathrm{~nm}$ from the Terra and Aqua MODIS aerosol products (MOD04L2, MYD04L2) are applied in this study. For the consistence in location and time of observations between AOD and SSR, we extracted the MODIS AOD over a $10 \times 10 \mathrm{~km}$ area, exactly covering the ground SSR site from both Terra and Aqua, which overpass Shanghai once a day at 09:00:00-10:00:00 LT (Terra) and 13:00:00-14:00:00 LT (Aqua). Therefore, the AOD used herein are composed of Terra-AOD and Aqua-AOD, each covering a period of 4 years from 1 January 2004 to 31 December 2007. Herein the AOD measurements with values are greater than 2.0 have been removed due to the large uncertainty in AOD retrieval algorithm which resulted in overestimate of MODIS AOD in and around Shanghai area (Pan et al., 2010). The DiSR and DfSR measured during 09:00:0010:00:00 LT and 13:00:00-14:00:00 LT, corresponding to the passage of Terra and Aqua, respectively, are also collected. Consequently, one valid Terra-AOD record corresponds to one DfSR and DiSR measurement, denoted as Terra-DiSR and Terra-DfSR, respectively. The same is done for Aqua$\mathrm{AOD}$ and the corresponding Aqua-DiSR and Aqua-DfSR.

\subsection{Methodology}

A 5-year moving average is used to describe the temporal change of DiSR and DfSR, especially to distinguish the dimming and brightening periods in their secular variations. The linear regression method is used to estimate the magnitude of dimming/brightening by $\mathrm{W} \mathrm{m}^{-2}$ decade $^{-1}$ with a t-test of $90 \%$ confidence or greater. The long term variations of DiSR and DfSR are investigated under both all-sky and clear-sky conditions. The linear regression is also done to analyze the relationship between AOD and corresponding DiSR and DfSR under clear-sky conditions in different seasons. The ttest method is also applied to determine whether the slope of the fitted trend is significant enough to have the confidence level reach $90 \%$ or greater.

Terra-AOD and the corresponding Terra-DiSR and TerraDfSR are examined for their weekly variations and the impact of AOD on DiSR and DfSR. The same procedure is also performed for Aqua-AOD and the associated Aqua-DiSR and DfSR in order to study the role of aerosol on SSR more fully and rigorously. All of the data used for weekly analysis meet the following requirements: the variable should be observed at least 2 days per week, of which at least 1 day among the weekdays (Tuesday to Friday) and 1 day among the weekends (Saturday to Monday). We choose to define the weekends as a 3-day period (from Saturday to Monday) rather than 2-day period (Saturday and Sunday) for the purpose of more robust statistics (Xia et al., 2008). All daily data for a week are converted as a percentage departure (\%) from the weekly average. This method can render weekly cycle evidently and has been carried out by Peterson et al. (1981) and Smirnov et al. (2002) for weekly analysis on AOD. Similar with the analysis technique for AOD weekly variation by Xia et al. (2008) and Quaas et al. (2009), we introduce the "weekend effect" to quantify the variable difference between weekdays and weekend. It is defined as the percentage difference of averaged departure of Tuesday, Wednesday, Thursday and Friday from the weekly average, and that of Saturday, Sunday and Monday, in order to quantify the variable difference between weekdays and weekends. The statistical significance is indicated when it exceeds a $90 \%$ confidence level based on the t-test technique.

\section{Results}

\subsection{The dimming and brightening characters in the secular variations of DiSR and DfSR}

Figures 1 and 2 present the long term variations of DiSR and DfSR from 1961 to 2008 under clear-sky and all-sky conditions, respectively. By 5-year average smoothing, the secular trends of DiSR in clear-sky and all-sky days are both divided into three successive periods, ranging from the end of 1960s to the mid 1980s, then to the mid 1990s, and thereafter. These three periods can be described as "dimming", "stabilization", and "renewed dimming" for clearsky days, and "dimming", "slight brightening", and "renewed dimming" for all-sky days. In the dimming periods, DiSR decreased dramatically from 1968-1984 with a $-34.2 \mathrm{~W} \mathrm{~m}^{-2}$ decade $^{-1}\left(-23.8 \%\right.$ decade $\left.^{-1}\right)$ trend for clearsky days and a $-15.5 \mathrm{~W} \mathrm{~m}^{-2}$ decade $^{-1}\left(-22.7 \%\right.$ decade $\left.^{-1}\right)$ decrease for all-sky days, both above $99 \%$ confidence. In the second period, DiSR remained stable in clear-sky days while it showed a slight brightening in all-sky days by an increase of $8.62 \mathrm{~W} \mathrm{~m}^{-2}$ decade $^{-1}\left(13.4 \%\right.$ decade $\left.^{-1}\right)$ with more than $90 \%$ confidence from 1984 to 1996 . A renewed dimming occurred for both all-sky and clear-sky days in the third period. DiSR decreased from 1996 to 2008 by $-6.9 \mathrm{~W} \mathrm{~m}^{-2} \mathrm{decade}^{-1}\left(-5.9 \% \mathrm{decade}^{-1}\right)$ for clear-sky days and $-5.3 \mathrm{~W} \mathrm{~m}^{-2}$ decade $^{-1}\left(-8.4 \%\right.$ decade $\left.^{-1}\right)$ for allsky days, but both without significant confidence. It suggests that such "dimming" and "renewed dimming" phenomenon are not only a characteristic in cloudy atmospheres but also are evident under cloudless skies, indicative of potential impacts on SSR through changes in aerosol emission related to economic development and air pollution regulation.

The secular variations of DfSR under all-sky and clearsky conditions show less coherence than that of DiSR from 


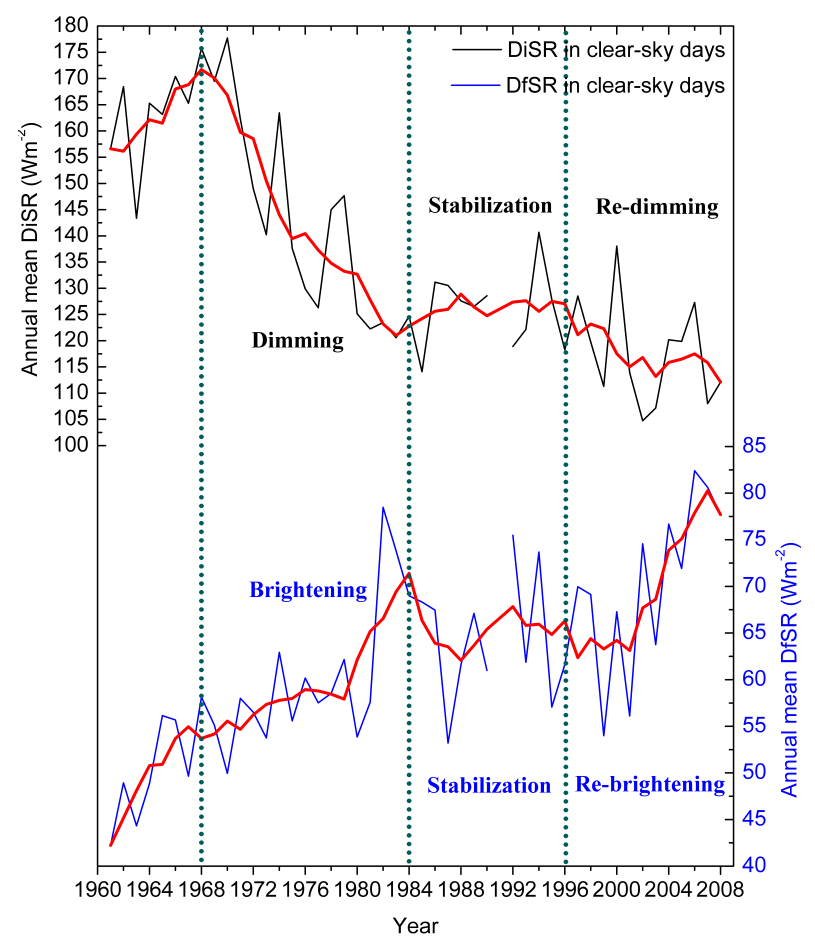

Fig. 1. Annual mean of direct surface solar radiation (DiSR, shown in black line) and diffuse surface solar radiation (DfSR, shown in blue line) observed on clear-sky days during the period of 19612008 in Shanghai. Five year moving averages are also shown in red lines. Units are $\mathrm{W} \mathrm{m}^{-2}$.

1961 to 2008. Overall, DfSR increased significantly from 1961 to 2008 in clear-sky days by $5.2 \mathrm{~W} \mathrm{~m}^{-2}$ decade $^{-1}$ $\left(8.3 \%\right.$ decade $\left.^{-1}\right)$ with $99 \%$ confidence. However, the oscillated inter-annual variability of DfSR was observed in all-sky days with a few peaks around 1982, 1992 and 2007 without a very significant increasing trend compared to that in a cloud free condition. Similar studies have also been conducted by Qian et al. (2006) and they suggested that the lack of increase in all-sky diffuse radiation might be due to the concurrent decrease in cloudiness.

It is noteworthy to mention that during the two dimming periods of DiSR, DfSR presented an opposite trend of remarkable brightening under clear-sky conditions by $9.7 \mathrm{~W} \mathrm{~m}^{-2} \mathrm{decade}^{-1}\left(16 \% \mathrm{decade}^{-1}\right)$ and $15.5 \mathrm{~W} \mathrm{~m}^{-2}$ decade $^{-1}\left(22 \% \mathrm{decade}^{-1}\right)$, respectively, and both above $99 \%$ confidence. DfSR also leveled off from the mid 1980s to the mid 1990s corresponding to the stabilization of DiSR during the same period. An increase in the diffuse radiation can be expected in areas with strong dimming of DiSR owing to enhanced scattering in the atmosphere from the increased aerosol loads under clear sky conditions. It implies that increased aerosol loading resulting in a decrease in atmospheric transparency plays an important role on DiSR dimming and corresponding brightening of DfSR on cloud-free days in the Shanghai megacity.

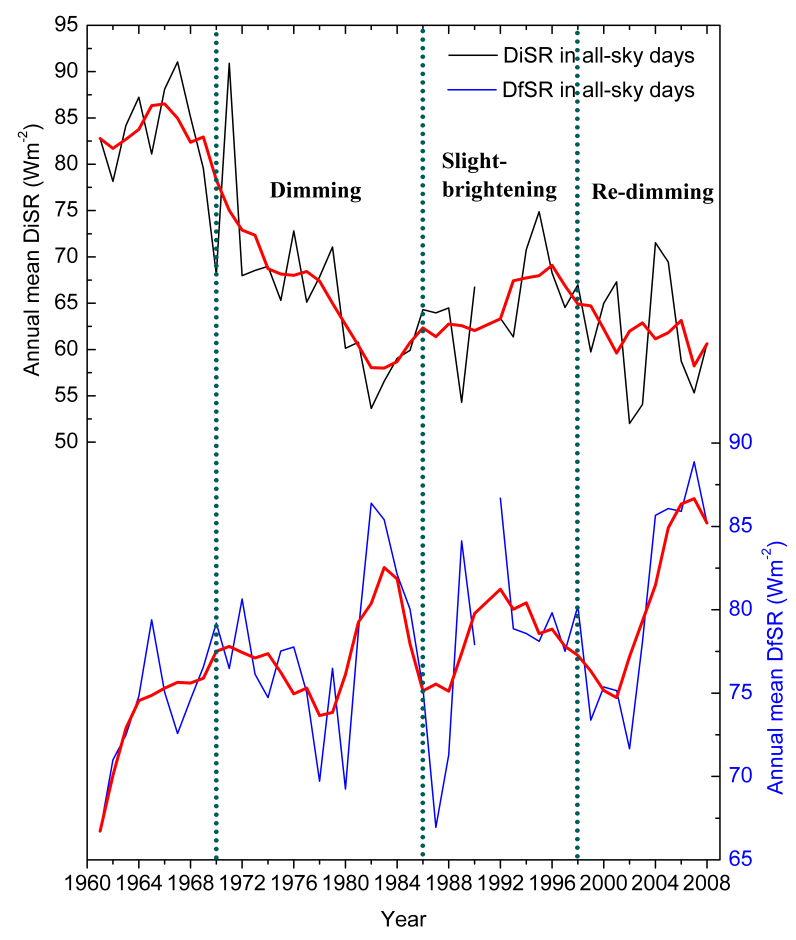

Fig. 2. Same as Fig. 1, but for all-sky days.

\subsection{The relationships between AOD and DiSR and DfSR}

Atmospheric aerosols can directly modify SSR by scattering and/or absorbing solar radiation during its path from the top of the atmosphere to the surface of the Earth. In general, increasing column-integrated aerosols can lead to a decline in DiSR under clouds free conditions. However, if the increasing aerosols have not yet exceeded a threshold they will lead to an increase in DfSR, otherwise, the extreme heavy aerosol loading will also lead to a decline in DfSR (such as heavy dust-storm). In this section, the relationships between AOD and DiSR and DfSR under cloud free condition are investigated based on the MODIS AOD and corresponding hourly DiSR and DfSR measurements in Shanghai. The study period ranges from 1 January 2004 to 31 December 2007. Considering the seasonal changes of DiSR, DfSR and AOD, we analyze the data from seasonal collections instead of from whole year data sets. There are 264 AOD samples in spring (defined as March, April and May), 172 samples in summer (defined as June, July and August), 186 samples in autumn (defined as September, October and November), and 109 samples in winter (defined as December, January and February). Figures 3-6 showed the scatter plots of AOD vs. DiSR and AOD vs. DfSR for the four seasons. We can see that AOD is significantly correlated with DfSR, and anti-correlated with DiSR in all seasons, both above $99 \%$ confidence, indicating that the increase (decrease) of AOD will change the atmospheric transparency notably so as to 


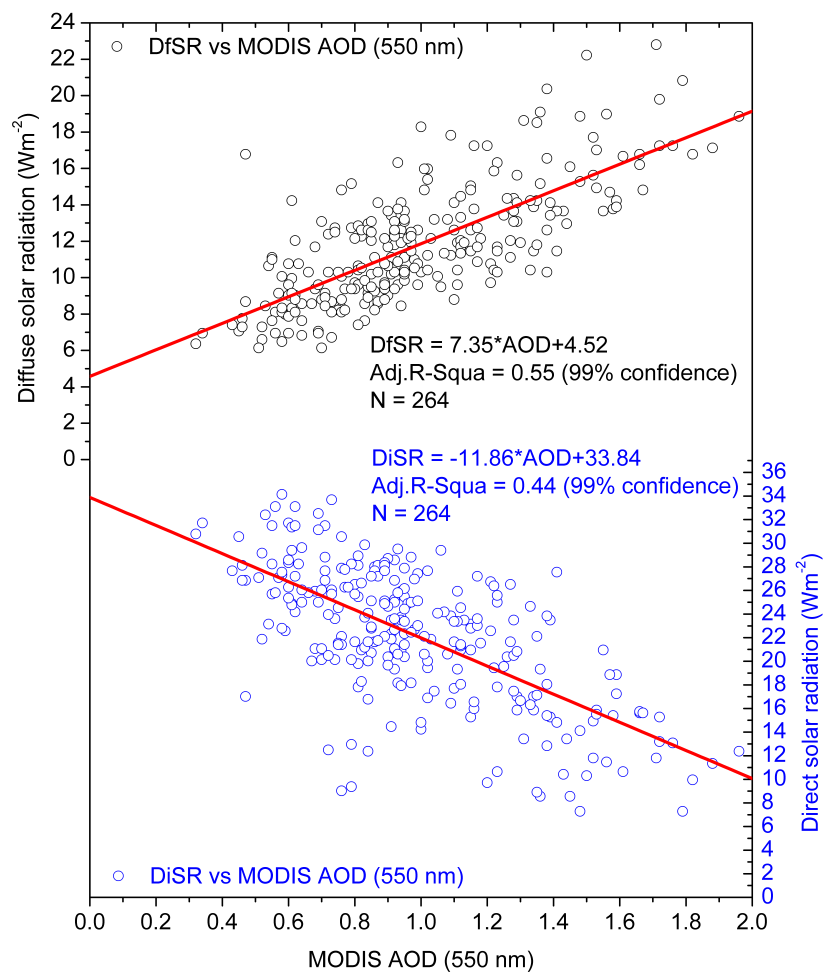

Fig. 3. Scatter plots of AOD and DfSR (denoted by black cycles on the top) and DiSR (denoted by blue cycles on the bottom) measured in spring from 2004 to 2007 in Shanghai. The AOD data is from the daily level 2 MODIS Aqua and Terra products (collection 005) at $550 \mathrm{~nm}$. The DiSR and DfSR were measured during the satellite passage over this area. Linear fittings are red lines.

enhance (decline) the DfSR, and decline (enhance) the DiSR simultaneously. DiSR and DfSR are affected by AOD most significantly in spring with a $-1.19 \mathrm{~W} \mathrm{~m}^{-2}$ decrease and a $0.735 \mathrm{~W} \mathrm{~m}^{-2}$ increase per 0.1 AOD increase, respectively, with above $99 \%$ confidence. The significant relationships between AOD and DiSR and DfSR abovementioned directly proved the great impact of ambient aerosol on SSR under clear skies. Thus we speculated that aerosol is a potential modulator for SSR dimming and brightening during its long term variations.

The difference of the correlations between AOD and SSR among spring, summer, autumn and winter indicates the seasonal variations of the aerosol optical properties. Based on the MODIS AOD measurements from 2004 to 2007, the mean Terra AOD in Shanghai megacity is $1.00,0.98,0.69$, 0.66, and the mean Aqua AOD is 1.06, 0.97, 0.73, 0.72 for spring, summer, autumn, winter respectively. It is worth to note that the AOD in Shanghai megacity show obvious seasonal difference, in spring and summer AOD is much higher than that in autumn and winter. This is possibly attributed to the regional climate which has an important role on the dynamical and chemical processes of aerosol such as the peripheral aerosol transportation, mixing layer height which

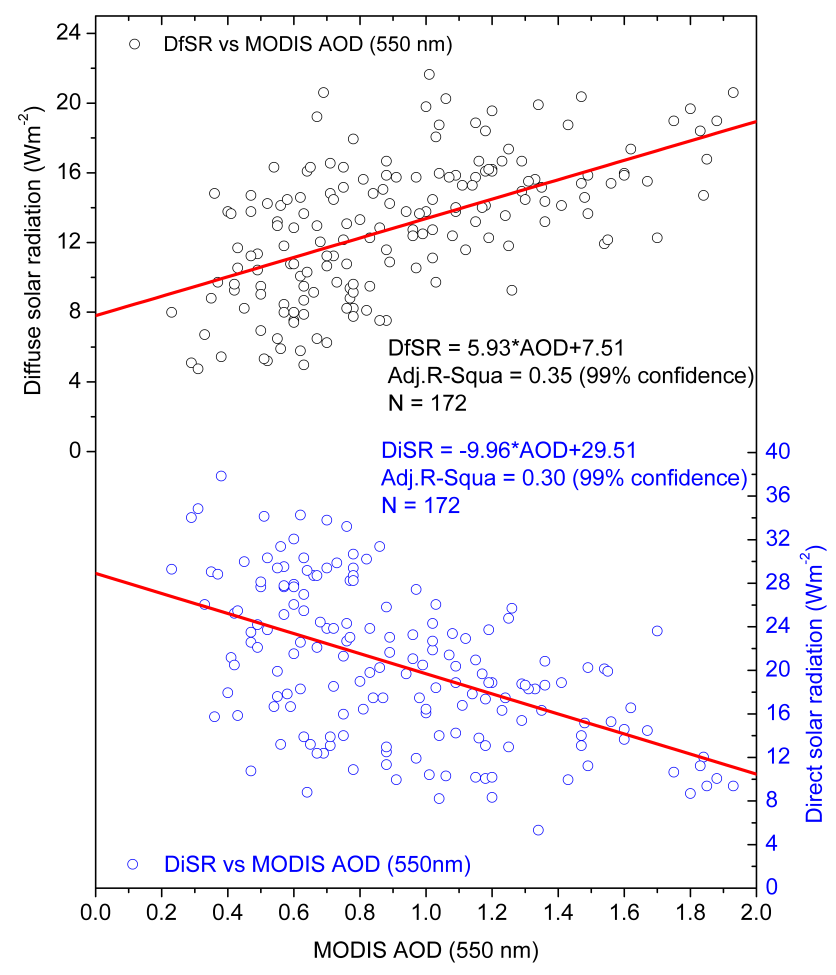

Fig. 4. Same as Fig. 3, but in summer.

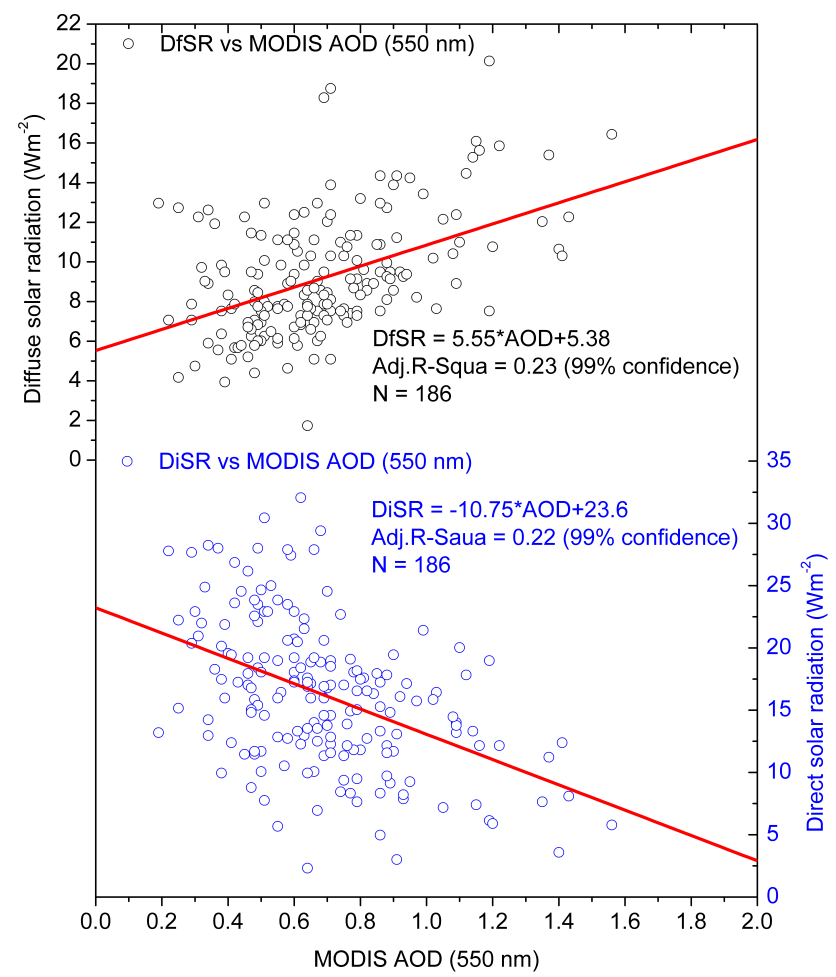

Fig. 5. Same as Fig. 3, but in autumn. 


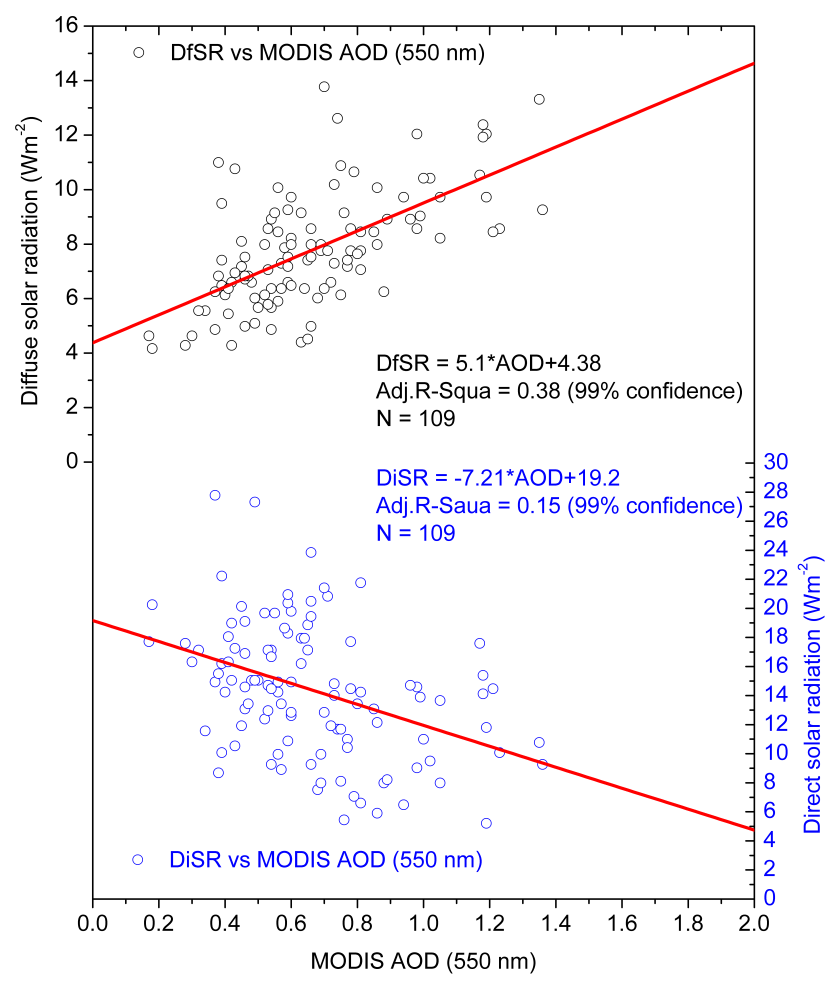

Fig. 6. Same as Fig. 3, but in winter.

impacts the aerosol vertical distribution, as well as the gasparticulate transformation ( $\mathrm{Li}$ et al., 2003). In spring, frequent dust storm originated from North China can affect east of China significantly ( $\mathrm{Li}$ et al., 2003). The migration of the dust storm transports large number of coarse particulate matters from north to south in China, thus enhancing the aerosol level and leading to high AOD in the Yangtze Delta region including Shanghai megacity. In summer, the weather in Shanghai is typically hot and wet, which is beneficial for the gas-particulates transformation process and the hydroscopic increasing in diameter size of water-soluble aerosols. The two processes tend to mutually result in high AOD in this season despite the wet removal on ambient aerosol by precipitation during Meiyu period. In autumn and winter, AOD values in Shanghai decrease dramatically compared to those in spring and summer, and usually reach the minimum in winter. In these two seasons, Shanghai is always controlled by the cold high pressure. The westerly and northerly prevail in this area with high velocity both on surface and high level, leading to good dispersion condition for airborne pollutants. Therefore in autumn and winter the AOD is quite lower than that in the other two seasons. As pointed out by $\mathrm{Li}$ et al. (2003), besides regional climate, there are some other elements can influence the vertical distribution of aerosol significantly such as Land Use/Land Cover Change (LUCC), local emission, etc. So detailed investigations on the seasonal variation of AOD in Shanghai megacity should be performed in the future studies.

\subsection{Weekly cycles of AOD, DiSR, and DfSR}

As we known, aerosol can be exhausted from either anthropogenic origins such as industrial activities and transportations, or natural sources e.g., sea salt and volcanic eruption. Both of them can modify SSR by scattering and/or absorbing solar radiation in the atmosphere. Streets et al. (2009) estimated that natural contributions to aerosol optical depth over 1980 to 2006 showed no significant trends $\left(<1 \%\right.$ year $\left.^{-1}\right)$, except for a small increase in Europe and a small decrease in South America and Southeast Asia. This suggests that anthropogenic aerosols indeed play a dominant role in the decadal variations of aerosol optical depth, furthermore affect SSR changes probably in many areas. In this section, we will depict the impact of anthropogenic activities on AOD and corresponding DiSR and DfSR by weekly analysis.

Based on multi-year MODIS AOD data, Xia et al. (2008) reported that during the weekdays, the MODIS AOD over much of eastern China is generally less than that during the weekends, especially in the Yangtze River Delta (YRD) region. On the other hand, measurements made in Shanghai indicate that the surface concentration of $\mathrm{NO}, \mathrm{NO}_{2}, \mathrm{O}_{3}$ and surface Aerosol Scattering Coefficient (ASC) exhibit clear weekly cycles. During the weekdays, $\mathrm{NO}_{\mathrm{x}}$ and ASC are significantly larger, while $\mathrm{O}_{3}$ is lower than that during the weekends (Geng et al., 2008; Xu et al., 2009). These cycles are likely due to the anthropogenic activities, such as traffic and industrial related emissions, which are reduced during the weekend. Studies done for the large cities in the US and Central Europe also showed the similar weekly cycles for AOD (Jin et al., 2005; Bäumer et al., 2008).

The seemingly inconsistency of AOD weekend effects between Xia et al.'s (2008) study and those of Geng et al. (2008) and Xu et al. (2009) are perhaps because Xia et al. (2008) used the MODIS Terra level-3 products (collection 005) with $1^{\circ} \times 1^{\circ}$ resolution, which represents the characteristics of AOD in a large scale. Furthermore, the ground-based AOD observation Xia et al. (2008) used is over a rural site which is located at the edge of the Taihu Lake, and is about 150 kilometers away from the Shanghai megacity. They found that AOD at $440 \mathrm{~nm}$ on Sunday exceeds the weekly mean by $10 \%$ at this site. In this study, we use both Terra and Aqua AOD data from MODIS level-2 products (collection 005 ) with much finer resolution of $10 \mathrm{~km} \times 10 \mathrm{~km}$, thus has the ability to reveal the AOD variation in more detail within a limited area. In fact, on an urban scale, the weekend effect of AOD has been reported in some megacities (Jin et al., 2005), such as New York City, which has much similarity with Shanghai in terms of urban area, population, and the amount of vehicles in the city.

In Fig. 7, Terra-AOD is obviously lower on Saturday and Sunday than its weekly average, which is corresponded by the significance of higher DiSR and lower DfSR in the same days, while on Wednesday and Friday, it exhibits an opposite pattern in which greater Terra-AOD is observed 
Table 1. AOD Percentage Departure from Weekly Average at $440 \mathrm{~nm}$ at Shanghai Pudong Site $(\%)$, the italic numbers indicates that the values are different from the weekly average above $90 \%$ confidence.

\begin{tabular}{lllllll}
\hline Mon & Tue & Wed & Thu & Fri & Sat & Sun \\
\hline 3.25 & 4.57 & -2.82 & 15.5 & -1.04 & -17.6 & -6.02 \\
\hline
\end{tabular}

and simultaneously accompanied by higher DfSR, and less DiSR than their weekly averages. Through the analysis of weekly cycles for 104 weeks, the mean weekend effect of Terra-AOD, Terra-DiSR and Terra-DfSR are determined to be $2.5 \%,-10.1 \%$ and $6.7 \%$, respectively, and all above $90 \%$ confidence. Aqua-AOD (in Fig. 8) is remarkably smaller on Monday and Sunday, with higher DfSR and lower DiSR compared to their weekly averages. On the contrary, on Tuesday, Thursday and Friday, Aqua-AOD is larger than the weekly average. Meanwhile, Aqua-DfSR and Aqua-DiSR are higher and lower than their weekly averages, respectively. The averaged weekend effect of Aqua-AOD calculated from a total of 76 weeks' valid data is $5.2 \%$ and the corresponding weekend effects of Aqua-DiSR and Aqua-DfSR are -4.18\% and $2.7 \%$, respectively. On average, both Terra and Aqua AOD on weekends are lower than that on weekdays perhaps due to the reduced anthropogenic aerosol emissions resulting from the lessening of transportation, industrial production and other human activities on weekends. Reduced AOD on weekends significantly enhanced atmospheric transparency under cloud free conditions so as to increase the DiSR and decrease the DfSR. It is suggested that aerosol loading exhausted from anthropogenic activities has an important role on SSR in Shanghai through the scattering and/or absorbing of incoming solar radiation on clear-sky days.

In addition to the instruments aboard on the satellite, AOD can also been measured by the ground-based equipments. In 2007, Shanghai meteorological bureau started to operate ground-based AOD measurements in an urban site which is located in the Shanghai Pudong New Area $\left(31.22^{\circ} \mathrm{N} 121.55^{\circ} \mathrm{E}\right)$. This site belongs to the China Aerosol Remote Sensing Network (CARSNET) and is about $15 \mathrm{~km}$ away from the pyranometer site where DiSR and DfSR were measured. The Cimel 318 sun/sky radiometer is applied to AOD observations at this site. Detailed information about the instrument calibration and data processing method has been introduced by Pan et al. (2010). For the purpose of examining the AOD weekend effect in the Shanghai megacity more comprehensively, daily mean AOD measured at $440 \mathrm{~nm}$ in this ground-based urban site from 16 February 2008 to 18 February 2009 are analyzed herein to investigate its weekly variations.

The weekly cycle of percentage departure of AOD from the weekly average observed at the Pudong ground-based site is presented in Table 1. The maximum AOD occurs on

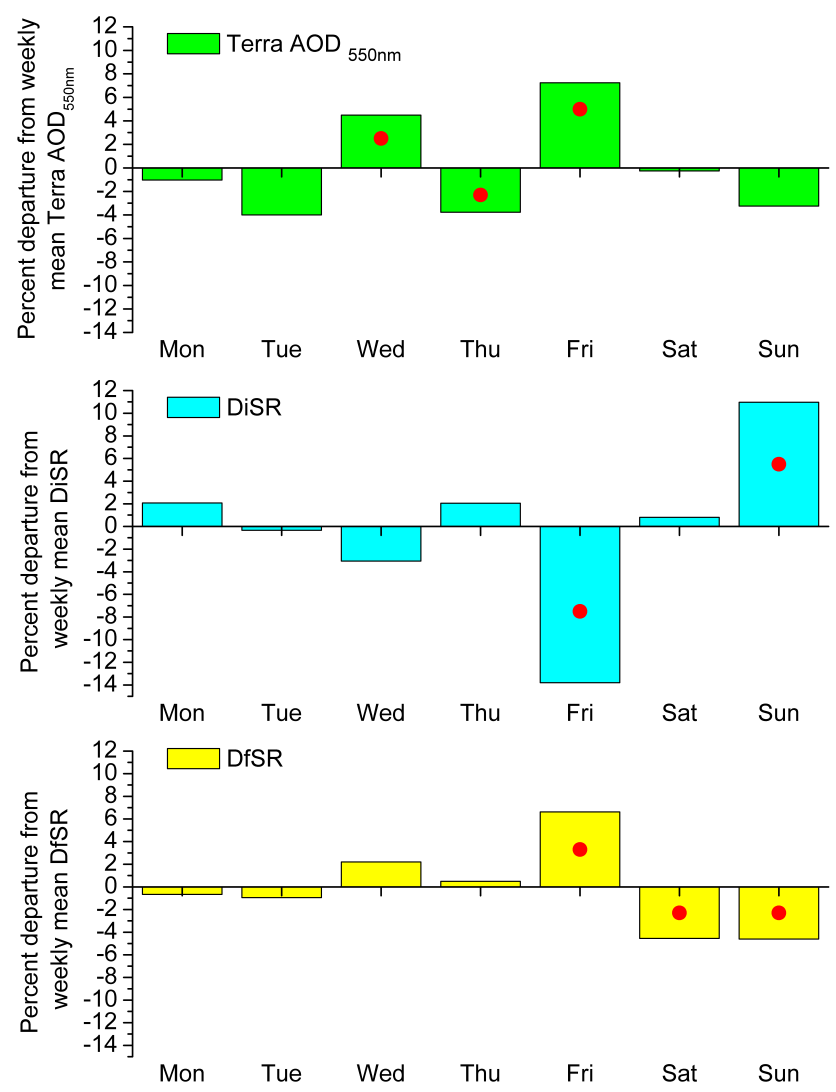

Fig. 7. Percentage departures of AOD (top), DiSR (middle) and DfSR (bottom) from their weekly averages in Shanghai. Red filled circles mean the departure from weekly average is above $90 \%$ confidence. The AOD data are from the MODIS Terra Level 2 products (collection 005) at $550 \mathrm{~nm}$. Terra overpasses Shanghai between 09:00:00-10:00:00 LT each day. The DiSR and DfSR are measured from 09:00:00 to 10:00:00 LT, in line with the satellite passage. Statistical data range from 1 January 2004 to 31 December 2007.

Thursday and is $15.5 \%$ larger than the weekly average. Saturday and Sunday have the two minimum AODs during the week and are lower than the weekly average by $17.6 \%$ and $6 \%$, respectively. The weekend effect of the AOD observed at this ground-base site is $10.7 \%$ based on the 38 weeks of valid data, which is in line with the weekend effect as seen from the MODIS AOD analysis. Furthermore, the ASC measured in the same site also showed a similar weekly character that the diurnal concentration of ASC on weekend was significantly lower than that on weekdays (Xu et al., 2009).

\section{Discussions and conclusions}

The decadal variation of SSR plays an important role on global and regional climate change. Since the global dimming and partial brightening of SSR has been reported from global to regional scales, more and more studies pay great attention to the contributions of aerosols or/and clouds on SSR. 


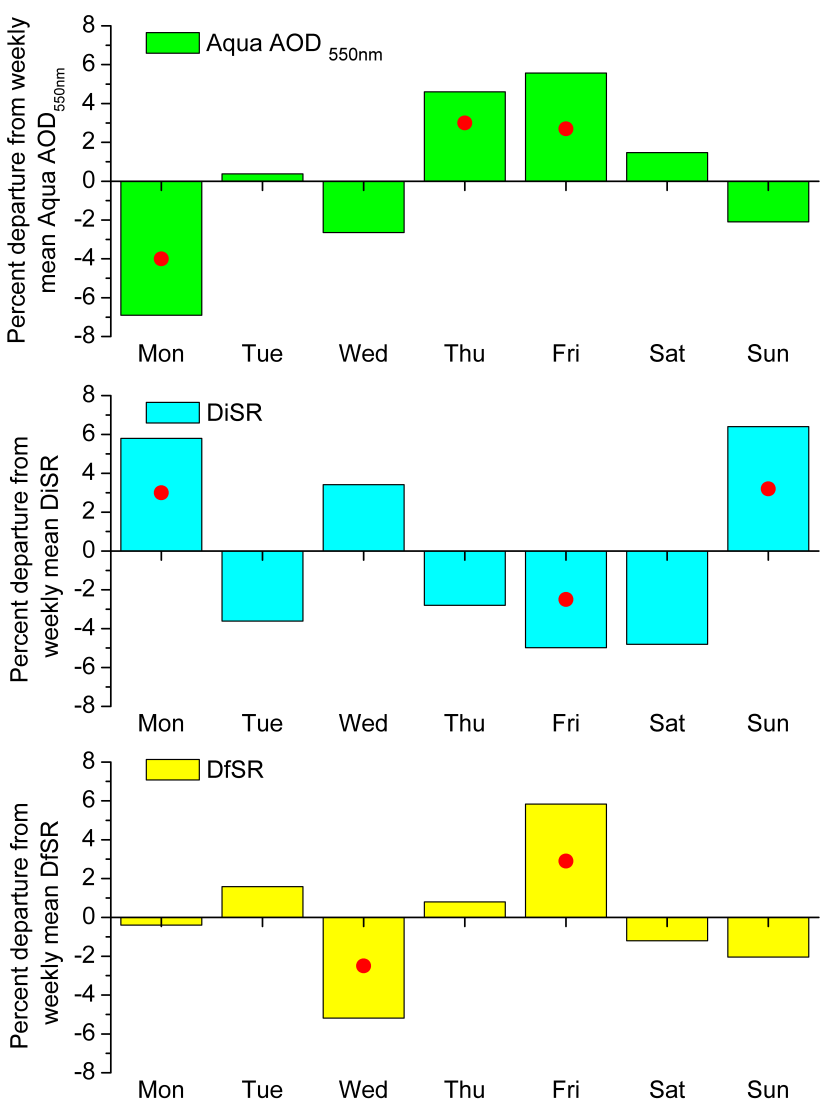

Fig. 8. Same as Fig. 7, but for the AOD data are from the MODIS Aqua products at $550 \mathrm{~nm}$. Aqua overpasses Shanghai between 13:00:00-14:00:00 LT each day. The DiSR and DfSR data are measured from 13:00:00 to 14:00:00 LT, in line with the satellite passage.

However these two factors interact strongly with each other and are difficult to be treated individually. Investigation on SSR variations under clear-sky condition has been regarded as an effective way to exclude the impact of cloud on SSR so as to explore solely the contribution of aerosols. Several studies have already shown that the SSR dimming before the mid 1980s in China was caused by the increasing aerosol loading during that time (e.g., Che et al., 2005; Streets et al., 2006; Qian et al., 2006, 2007; Shi et al., 2008; Wild et al., 2009). In this study, we reveal the three successive periods of dimming, stabilization and renewed dimming in the secular variation of DiSR during 1961-2008 under clearsky conditions in Shanghai. During the two dimming periods of DiSR, DfSR brightened significantly, indicating that the above mentioned dimming and brightening of DiSR and DfSR, respectively, on clear-sky days are the consequence of the decline in atmospheric transparency due to the change of aerosol emissions. Through the analysis on relations between the MODIS AOD records and associated hourly measurements of DiSR and DfSR, it has been found that AOD shows significant correlation and anti-correlation with DiSR and DfSR, respectively, and both above $99 \%$ confidence in all seasons. It further proved that ambient aerosols have important impacts on SSR by changing the atmospheric transparency due to the abilities of absorption and/or scattering of SSR.

Aerosols come from not only anthropogenic origins but also natural sources. We conducted the preliminary study on the influence of human activities on SSR by performing weekly cycle analysis on Terra-AOD and Aqua-AOD as well as the corresponding DiSR and DfSR. We found that both Terra and Aqua AOD show clear weekend effects. On weekends, AOD is lower than the weekly average, corresponded by higher DiSR and lower DfSR. While on weekdays, AOD, DiSR, and DfSR show opposite patterns compared to those on weekends. Higher AOD and DfSR, and lower DiSR are observed simultaneously. Less AOD on weekends due to the reduction of transportation and industrial production enhanced atmospheric transparency under cloud free conditions so as to increase the DiSR and decrease the DfSR. It is suggested that aerosol loading related to anthropogenic activities is an important modulator for decadal variation of SSR.

In addition to aerosol loading, aerosol compositions also change with the changes of the fuel types and the development of fuel utilization technology, which in turn will modify the aerosol scattering and/or absorption abilities. The change of scattering and absorption characteristics of ambient aerosols is a key in understanding the contribution of anthropogenic aerosols on SSR. However, it is beyond the scope of this study, but will be investigated in the future studies to further understand the impact of aerosols on direct and diffuse radiation.

Acknowledgements. This study is supported by the Key Basic Research Program of Science and Technology Commission of Shanghai Municipality under Grant No. 08JC1418300, Special Project for Scientific Research for Public Industry of CMA under Grant No. GYHY200906026, and the National Natural Science Foundation of China (NSFC) No. 41001283 and 40775002.

Edited by: X. Tie

\section{References}

Bäumer, D., Rinke, R., and Vogel, B.: Weekly periodicities of Aerosol Optical Thickness over Central Europe - evidence of an anthropogenic direct aerosol effect, Atmos. Chem. Phys., 8, 8390, doi:10.5194/acp-8-83-2008, 2008.

Che, H. Z., Shi, G. Y., Zhang, X. Y., Arimoto, R., Zhao, J. Q., Xu, L., Wang, B., and Chen, Z. H.: Analysis of 40 years of solar radiation data from China, 1961-2000, Geophys. Res. Lett., 32, L06803, doi:10.1029/2004GL022322, 2005.

Chu, D. A., Kaufman, Y. J., Ichoku, C., Remer, L. A., Tanré, D., and Holben, B. N.: Validation of MODIS aerosol optical depth retrieval over land, Geophys. Res. Lett., 29(12), 8007, doi:10.1029/2001GL013205, 2002. 
Geng, F., Tie, X., Xu, J., Zhou, G., Peng, L., Gao, W., Tang, X., and Zhao, C.: Characterizations of ozone, $\mathrm{NO}_{\mathrm{X}}$, and VOCs measured in Shanghai, China, Atmos. Environ., 42, 6873-6883, doi:10.1016/j.atmosenv.2008.05.045, 2008.

Jin, M., Shepherd, J. M., and King, M. D.: Urban aerosols and their variations with clouds and rainfall: A case study for New York and Houston, J. Geophys. Res., 110, D10S20, doi:10.1029/2004JD005081, 2005.

Kaufman, Y. J., Tanré, D., Remer, L. A., Vermote, E. F., Chu, A., and Holben, B. N.: Operational remote sensing of tropospheric aerosol over land from EOS moderate resolution imaging spectroradiometer, J. Geophys. Res., 102(D14), 17051-17067, doi:10.1029/96JD03988, 1997.

Levy, R. C., Remer, L. A., and Dubovik, O.: Global aerosol optical properties and application to Moderate Resolution Imaging Spectroradiometer aerosol retrieval over land, J. Geophys. Res., 112, D13210, doi:10.1029/2006JD007815, 2007.

Li, C. C., Mao, J. T., Alexis, L., Chen, J. C., Yuan, Z. B., Liu, X. Y., Zhu, A. H., and Liu, G. Q.: Characteristics of distribution and seasonal variation of aerosol optical depth in Eastern China with MODIS products, Chinese Sci. Bull., 48, 2094-2100, 2003.

Li, J. P., Wu, Z. W., Jiang, Z. H., and He, J. H.: Can global warming strengthen the East Asian summer monsoon?, J. Climate, 23, 6696-6705, doi:10.1175/2010JCLI3434.1, 2010.

Liang, F. and Xia, X. A.: Long-term trends in solar radiation and the associated climatic factors over China for 1961-2000, Ann. Geophys., 23, 2425-2432, doi:10.5194/angeo-23-2425-2005, 2005.

Mi, W., Li, Z., Xia, X., Holben, B., Levy, R., Zhao, F., Chen, H., and Cribb, M.: Evaluation of the moderate resolution mmaging spectroradiometer aerosol products at two Aerosol Robotic Network stations in China, J. Geophys. Res., 112, D22S08, doi:10.1029/2007JD008474, 2007.

Norris, J. R. and Wild, M.: Trends in aerosol radiative effects over China and Japan inferred from observed cloud cover, solar "dimming," and solar "brightening", J. Geophys. Res., 114, D00D15, doi:10.1029/2008JD011378, 2009.

Pan, L., Che, H., Geng, F., Xia, X., Wang, Y., Zhu, C., Chen, M., Gao, W., and Guo, L.: Aerosol optical properties based on ground measurements over the Chinese Yangtze Delta Region, Atmos. Environ., 44, 2587-2596, doi:10.1016/j.atmosenv.2010.04.013, 2010.

Peterson, J. T., Flowers, E. C., Berri, G. J., Reynolds, C. L., and Rudisill, J. H.: Atmospheric turbidity over central North Carolina, J. Appl. Met., 20, 229-241, 1981.

Qian, Y., Kaiser, D. P., Leung, L. R., and Xu, M.: More frequent cloud-free sky and less surface solar radiation in China from 1955 to 2000, Geophys. Res. Lett., 33, L01812, doi:10.1029/2005GL024586, 2006.

Qian, Y., Wang, W., Leung, L. R., and Kaiser, D. P.: Variability of solar radiation under cloud-free skies in China: The role of aerosols, Geophys. Res. Lett., 34, L12804, doi:10.1029/2006GL028800, 2007.
Quaas, J., Boucher, O., Jones, A., Weedon, G. P., Kieser, J., and Joos, H.: Exploiting the weekly cycle as observed over Europe to analyse aerosol indirect effects in two climate models, Atmos. Chem. Phys., 9, 8493-8501, doi:10.5194/acp-9-8493-2009, 2009.

Remer, L. A., Kaufman, Y. J., Tanré, D., Mattoo, S., Chu, D. A., Martins, J. V., Li, R. R., Ichoku, C., Levy, R. C., Kleidman, R. G., Eck, T. F., Vermote, E., and Holben, B. N.: The MODIS aerosol algorithm, products, and validation, J. Atmos. Sci., 62(4), 947-973, doi:10.1175/JAS3385.1, 2005.

Shi, G. Y., Hayasaka, T., Ohmura, A., Chen, Z. H., Wang, B., Zhao, J. Q., Che, H. Z., and Xu, L.: Data quality assessment and the long-term trend of ground solar radiation in China, J. Appl. Meteor. Climatol., 47, 1006-1016, doi:10.1175/2007JAMC1493.1, 2008.

Smirnov, A., Holben, B. N., Eck, T. F., Slutsker, I., Chatenet, B., and Pinker, R. T.: Diurnal variability of aerosol optical depth observed at AERONET (Aerosol Robotic Network) sites, Geophys. Res. Lett., 29(23), 2115, doi:10.1029/2002GL016305, 2002.

Streets, D. G., Wu, Y., and Chin, M.: Two-decadal aerosol trends as a likely explanation of the global dimming/brightening transition, Geophys. Res. Lett., 33, L15806, doi:10.1029/2006GL026471, 2006

Streets, D. G., Yan, F., Chin, M., Diehl, T., Mahowald, N., Schultz, M., Wild, M., Wu, Y., and Yu, C.: Discerning human and natural signatures in regional aerosol trends, 1980-2006, J. Geophys. Res., 114, D00D18, doi:10.1029/2008JD011624, 2009.

Wild, M.: Global dimming and brightening: A review, J. Geophys Res., 114, D00D16, doi:10.1029/2008JD011470, 2009.

Wild, M., Gilgen, H., Roesch, A., Ohmura, A., Long, C. N., Dutton, E. G., Forgan, B., Kallis, A., Russak, V., and Tsvetkov, A.: From dimming to brightening: decadal changes in solar radiation at Earth's surface, Science, 308, 847-850, doi:10.1126/science.1103215, 2005.

Wu, Z. W., Wang, B., Li, J. P., and Jin, F. F.: An empirical seasonal prediction model of the East Asian summer monsoon using ENSO and NAO, J. Geophys. Res., 114, D18120, doi:10.1029/2009JD011733, 2009.

Xia, X.: A closer looking at dimming and brightening in China during 1961-2005, Ann. Geophys., 28, 5, 1121-1132, doi:10.5149/angeo-28-1121-2010, 2010.

Xia, X., Eck T. F., Holben, B. N., Phillippe, G., and Chen, H. B.: Analysis of the weekly cycle of aerosol optical depth using AERONET and MODIS data, J. Geophys. Res., 113, D14217, doi:10.1029/2007JD009604, 2008.

Xu, J., Geng, F., Gao, W., and Zhen, C.: Aerosol scattering coefficient and the factors affecting them in Shanghai Pudong, Acta Sci. Circumstantiae, 30, 211-216, 2009.

Yang, J. M., Qiu, J. H., and Zhao, Y. L.: Validation of Aerosol Optical Depth from Terra and Aqua MODIS retrievals over a tropical coastal site in China, Atmos. Ocean. Sci. Lett., 3, 36-39, 2010. 